\title{
Maximum Heart Rate
}

National Cancer Institute

\section{Source}

National Cancer Institute. Maximum Heart Rate. NCI Thesaurus. Code C39779.

The minimum time between successive cycles of contraction and subsequent relaxation

of the heart, usually expressed as beats per minute, obtained from a set of

measurements of the heart rate. 